\title{
Positive Organizational Behavior Application in Modern Enterprise Management
}

\author{
Yu Zhou \\ Business School, Yunnan Normal University, Kunming Yunnan, 650106, China
}

Key words: Modern enterprise management, Organizational behavior, Applications.

\begin{abstract}
Under the background of economic globalization and the society information, enterprise management continues to carry out reform and innovation, organizational behavior theory began to emerge in business management, and has achieved good results; it has significant role in promoting enterprise management. This paper specifically analyzed the application of behavior for the modern enterprise management, hoping to provide some reference for enterprise management.
\end{abstract}

\section{Introduction}

Organizational Behavior is China's modern enterprise management applications widely as a discipline theory, the theory of knowledge related to psychology, political science, economics, management science and other fields. Through this integrated management to guide the activities of the enterprise and organizational behavior. Organizational behavior in management is to study the behavior and community relations employees, can provide some guidance for employees material and spiritual aspects of the initiative and creativity of the increase. So the theory of organizational behavior and human resource management of enterprises to improve business performance has very important significance.

\section{Conceptual Analysis of Organizational Behavior}

\section{Analysis from individual psychological and behavioral}

Individual psychological dynamic behavior is to analyze the contents of the working status of employees, life and values, ability and so on, through the analysis of these elements can reflect the ability of staff to complete the work. Enterprises in order to achieve better development must be the depth of mining potential of staff, staff of the enterprise and enhance the sense of identity and belonging, so as to continuously improve work efficiency. During the study of individual psychology and behavior of employees in both studies also included the idea of dynamic behavior dynamics of employees. So effective understanding of the behavior of employees and ideological trends contribute to stimulate the enthusiasm of employees, improve work efficiency, so that enterprises can improve performance and achieve the expected corporate earnings.

\section{Analysis from group psychology and behavioral}

Psychological and behavioral groups mainly refers to a company's staff can be for a common development goals, mutual cooperation, mutual help, mutual dependency, an activity so as to form a whole [1]. With respect to individual psychological behavior, the group psychological and behavioral development of enterprises have a greater role in the enterprise managers to improve the business performance of key elements. Group psychology and behavior by way of Dynamic groups publish task group to show the characteristics of form and structure of population groups, the objective conditions exist comprehensive decision.

Analysis from the organizational psychological dynamics and organizational behavior 
The production and operation in the presence of a particular relationship among employees, management companies will make the relationship between employees and the differences appear close or distant, or, which would produces different groups, the needs of these groups also exist vary widely [2]. Only through these organizations rational organization and management to be able to provide a more effective force for improving business performance. Business leaders are business activities and management of the organizer, so business leaders must master the psychology and behavior of different groups, group exhibit behavior that can provide the basis for the study of group psychology of the organizers, thus different groups reasonable control and deployment.

\section{Significance of organizational behavior in business management applications}

\section{Employees can get a sense of fairness}

Organization mainly composed by the team and the group, individual employees of enterprises and constitute the main members of the group and the team, in groups and everyone in the organization will pay attention to their sense of fairness, so companies in the management need to improve the employees sense of fairness seriously. If the company's employees in the group was unable to get a sense of fairness, very easy to make this part of the employees lost their motivation to work, thereby reducing the efficiency of the work, and even employees of collective resignation of the phenomenon. Sense of fairness referred to here is not simply pay equity. Organizational behavior theory in enterprise management pay more attention to psychological needs and personality characteristics of different employees work in the enterprise reflect the specific behavior performance. If employees believe that job suited to their own position, and the work environment and methods are more comfortable and be able to equal remuneration for work, then the employee's sense of fairness will be effectively improved to be able to dedicate myself to work, thus improving work efficiency.

\section{Enhance company's cohesion}

The company's internal cohesion is the basis for the development of enterprises, so enterprises in order to enhance the competitiveness of the market will focus on the internal sense of team culture. Many companies in the recruitment requirements highlight the "team." Organizational behavior theory to the management of its business is in the core meaning of text to people based on the role of business management. Enterprises need to do the internal cohesion of the people, by the spirit of enterprise employees' convergence a cohesiveness formed. And organizational behavior in business management application is just one of the needs-based, so the application of organizational behavior to business management can improve business performance.

\section{Corporate human resources integration}

The overall quality of employees of enterprises is the main driving force of modern enterprise development. From the organizational behavior perspective of business management research on corporate decision-making there is a certain positive significance, by analyzing the theory of organizational behavior technological innovation in personnel for effective development and use of effective optimization of the various positions of Human Resources configuration, can effectively avoid the waste of human resources [3]. Enterprise restructuring and human resources management, enabling staff positions and work more closely match, to meet the psychological needs of employees, so that employees can be better put to work; at the same time set a reasonable reward and punishment system in the management of human resources, will all employees are integrated into the management of enterprises, enhance the individual employee and the overall intervention, to improve the efficiency of enterprise management.

\section{Enhance work and life quality of employees}

In modern enterprises must adopt a scientific and rational approach to production planning and business management. And the production and management are inseparable from the support of employees, so only to protect the life and quality of work of employees to be able to stimulate higher employee enthusiasm. Organizational behavior in business management application with the staff's work and life have a great relationship, if poor environmental quality of life of employees, will 
seriously affect the efficiency of the staff; the other hand, if the employee living environment is favorable then you can promote employees better services for enterprises. Therefore, the application of organizational behavior to business management will help to improve the environment and quality of life of employees, and thus maximize the potential of employees, enhance production and operating efficiency.

\section{Problems in organizational behavior in enterprise management application}

\section{One-sided cognition for enterprise management of organizational behavior}

Organizational behavior achieved in our business management some success, many companies have recognized the organizational behavior importance of science in our business management, so are eager to introduce organizational behavior theory in their business management, but most Effective enterprise received is not satisfactory. Mainly because many companies do not know enough organizational behavior theory thorough and comprehensive, so the process of introduction of organizational behavior in too blind, resulting in organizational behavior cannot effectively play the role in the enterprise management. At the same time, organizational behavior and psychology are inseparable, so companies in the application of science in organizational behavior management must be counselors assist, psychological needs and personality traits of employees is analyzed and the analysis results to determine the degree of matching employees and positions, and then to effectively optimize staffing role. But many companies ignore the relationship between psychology and organizational behavior, and organizational behavior theory will only apply to the one-sided business management, science cannot be complete staffing, thereby promoting organizational behavior in business management applications cannot play effect.

\section{Lay no emphasis on the application of organizational behavior theory}

Organizational behavior in our state-owned enterprises as well as small and medium enterprises start relatively late, so many companies on organizational behavior is not enough to understand the effect, resulting in lack of business management theory of organizational behavior degree of importance. In the state-owned enterprises, mainly the implementation of human resource management system establishment, that is, management tenure, after the preparation of the staff made into the enterprise, equivalent Lift iron rice bowl, do not worry because of the low efficiency is dismissed, this management methods can not staff the implementation of incentives, it is difficult to inspire staff enthusiasm for work, so the efficiency of enterprises is difficult to be guaranteed; and management of small and medium enterprises, the lack of consideration of individual employee needs, so companies offer employees jobs as well as various aspects of treatment is difficult to meet the psychological needs of employees [4]. And the work incentives and promotion of SMEs is often inadequate, it is difficult to attract and retain talent, enterprise management is hampered, affecting the healthy and stable development of enterprises.

\section{Effective measures to improve enterprise management organizational behavior theory}

\section{Grasp the psychological needs and working conditions of employees}

Employees own needs can be effectively met, staff capabilities and character is suitable for its job all affect the work of state employees, and employee productivity and have a great relationship with the work of state employees, a serious impact on business complete organizational goals. In the high-paced living conditions, many employees are facing the dual pressures of family and work, and to some extent living and working there is a certain contradiction in itself, employees would often trade-off phenomenon. If the company can give employees a sense of belonging, it will employees with a sense of belonging to the family of offsetting, the equilibrium relationship between the two employees. Good managers able to implement organizational behavior from the perspective of business management, accurately grasp the contradictory nature of work and family, and to take effective measures to enable employees to effectively balance the two, and thus eliminate the contradiction between the two, so which can exist in harmony. In the management of enterprises, only 
fully understand the character and the staff needs to be able to objectively analyze staff positions and employees to set organizational behavior management, so that employees of the enterprise a sense of belonging, and thus more investment services for enterprises.

\section{Set positions and roles according to the characteristics of employees}

Managers understand the personality characteristics of staff before we can predict the work of the staff that may arise in certain jobs and the environment and attitudes, and human resources management to be more scientific and reasonable. Human resources research data analysis, employee personality There are five types are: export-oriented, stable, open, Responsible and pleasant type. The five character almost simultaneously present in each employee's body, but different people on this strong performance level five kinds of different personalities, which leads to the different personalities for different jobs, but also match the character and nature of work degree also seriously affect the efficiency of the staff.

\section{Organize employees by learning to enhance the competitiveness of enterprises}

Construction in the enterprise learning organization can improve staff awareness of the level of knowledge and ability to work, so managers and executives develop a knowledge-based, effective enterprise knowledge sharing and knowledge innovation ${ }^{[5]}$. In the context of economic globalization, the development of enterprises face competitive pressures increasing, and companies want to improve their competitiveness, we must continue to reserve knowledge, innovation and development on the basis of, and knowledge on reserves employees need to keep learning. Organizational behavior theory in business management, emphasizing employees on internal and external knowledge and learning sustained through continuous charging to achieve shared knowledge resources, enhance the overall level of knowledge enterprises, thereby strengthening the overall competitiveness of individual employees and enterprises force.

\section{Appropriate pressure mechanisms setting in enterprise management}

Business management, whether to build a learning organization or human resources reform will hear voices from different staff, different personalities of the staff of the enterprise management will be the attitude shown there is a big difference, and the organization will have a different attitude behavior have a certain impact. Staff reflects the organizational behavior in different, often reflected in the respective source of pressure and stress. If the work is facing some pressure, it will lead to staff feeling out of control, so that employees easily produce anxiety and frustration. But when employees come under pressure in the process so that problems can be solved effectively through coordination of resources and organization, but will then pressure into motivation, inspire staff initiative to improve work efficiency.

The effective implementation of the enterprise management theory for organizational behavior Enterprise Management of organizational behavior theory applications and dependence depends on the business productivity as well as capacity and quality managers. Although the role of science in business management from the point of view of organizational behavior, organizational behavior is applied to the field of business management, but all enterprises in the application of organizational behavior theory but also according to the specific situation of enterprises, step by step, step by step in a planned carried out. So that it can make organizational behavior management in the enterprise management root slowly, so as to play its due role in business management.

\section{Conclusion}

In summary, the enterprise application management organizational behavior management can effectively enhance the management capacity to stimulate the enthusiasm and creativity of employees to work, so as to enhance business performance. However, due to organizational behavior theory in our Enterprise Management Application time is still short, there are many immature place, so that all enterprises in the application of behavioral management in light of its own needs, the introduction of progressive, enabling it to play the biggest role in the enterprise management. 


\section{References}

[1] MA Qian, Pan Zheng. On the enterprise management efficiency enhancement role of organizational behavior. Value Engineering, 2012,31 (36): 144-145.

[2] Yuan Cijun, Ding Qigao. On the organizational behavior application in the enterprise management. Management observation, 2011 (27): 56.

[3] Qin Li. Implementation strategy for enterprise management based on organizational behavior analysis. Science and Innovation, 2014 (1): 77-78.

[4] Gao Caijun. Application research of modern enterprise management of positive organizational behavior. Chinese trade and economy, 2014 (21): 82-82.

[5] Wang Shun. Enterprise management strategy under organizational behavior perspective. New Economy (Theory Edition), 2013 (12): 373-373,375. 